
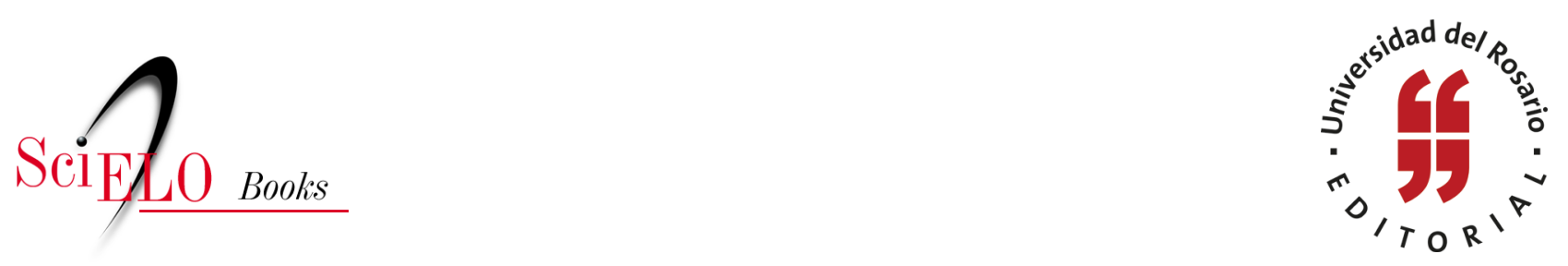

\title{
7. La emergencia del clientelismo como objeto visible del sistema político y la preeminencia de la visión negativa del fenómeno
}

\author{
Laura Daniela Guerrero García
}

\section{SciELO Books / SciELO Livros / SciELO Libros}

GUERRERO GARCÍA, L.D. La emergencia del clientelismo como objeto visible del sistema político y la preeminencia de la visión negativa del fenómeno. In: Clientelismo político, ¿desviación de la política o forma de representación?: Estado del arte sobre las aproximaciones al clientelismo en Colombia 1973-2011 [online]. Bogotá: Editorial Universidad del Rosario, 2014, pp. 85-90. Opera prima collection. ISBN: 978-958-738-552-6. https://doi.org/10.7476/9789587385526.0009.

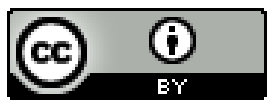

All the contents of this work, except where otherwise noted, is licensed under a Creative Commons Attribution 4.0 International license.

Todo o conteúdo deste trabalho, exceto quando houver ressalva, é publicado sob a licença Creative Commons Atribição 4.0.

Todo el contenido de esta obra, excepto donde se indique lo contrario, está bajo licencia de la licencia $\underline{\text { Creative }}$ Commons Reconocimento 4.0 . 


\section{La emergencia del clientelismo como objeto visible del sistema político y la preeminencia de la visión negativa del fenómeno}

Este capítulo busca esgrimir la hipótesis de trabajo que emergió de la revisión del estado del arte de los estudios de clientelismo en Colombia: la presencia de un mayor número de estudios sobre clientelismo donde el fenómeno es abordado desde una postura preeminentemente negativa puede ser explicada a partir de la creación de un discurso anti-clientelista que se gestó en el seno de la clase política, a raíz de un conflicto por el poder entre un sector modernizante e industrial y otro tradicional.

Se observa que la crisis del bipartidismo fue, en parte, producto de tres efectos de desestabilización del sistema. En palabras textuales de Francisco Gutiérrez:

Hay tres efectos de desestabilización, todos ellos verificados. Primero, una ruptura muy profunda entre el personal político tradicional y las élites socioeconómicas, sobre todo aquellas cuya actividad principal y residencia se encuentra en las grandes ciudades. Segundo, desprestigio y rechazo de dos de las instituciones claves de la vida política, Congreso y partidos. Este desprestigio ha ido acompañado de acciones concretas en varias direcciones 
comenzando con el encarcelamiento de decenas de congresistas liberales. Tercero, desestructuración de los partidos, al darle un gran margen de maniobra (gracias a recursos ilícitos), a grupos regionales y locales en su relación con la dirección partidista. ${ }^{141}$

El efecto bola de nieve sirve de analogía para explicar lo sucedido con estos tres efectos desestabilizadores del sistema. En primer lugar, la ruptura del personal político desencadenó un discurso abiertamente anti-clientelista, que tildaba de corruptos y anti-modernistas a los opositores a la reforma de 1968 o a los miembros de la oposición. En segundo lugar, se desprestigió a los cuerpos colegiados. Finalmente, se desestructuraron los partidos tradicionales. Así, el clientelismo aparece como objeto visible del sistema político colombiano en medio de una pugna por el poder político. Por esta razón, el discurso anti-clientelista no era consecuente en la eliminación del fenómeno. Por el contrario, este fue utilizado como mecanismo para desprestigiar al oponente, sin querer decir con ello que los políticos notables no hicieran uso de mecanismos clientelistas para mantenimiento y reproducción de su poder.

Lo anterior permite observar que existen elementos contradictorios entre el discurso que se generó alrededor del fenómeno y las medidas adoptadas para combatirlo. Las reformas institucionales que pretendían dar muerte al clientelismo sólo produjeron nuevos fenómenos aún más difíciles de combatir y unas dosis duplicadas de clientelismo. De esta manera, es posible pensar que la trasformación del fenómeno y la mezcla con otros problemas más complejos puede tener una profunda relación con la presencia

${ }^{141}$ Ver Gutiérrez Sanín y Dávila Ladrón de Guevara, "Paleontólogos”, 42. 
del narcotráfico y los grupos al margen de la ley en la política nacional. ${ }^{142}$

\subsection{Propagación del clientelismo y del discurso anti-clientelista}

Jaime Arocha traduce una cita de un experto en sistemas en la cual explica lo que sucede cuando se implementan medidas para modificar un sistema sin saber a ciencia cierta los posibles efectos: ${ }^{143}$

Machetear es [...] “disminuir irregularidades sin habili-
dad o propósito definido"; [...] cuando un sistema cons-
truido de esta forma comienza a crecer, se hace más y más
inestable. Si uno de sus subsistemas falla de una manera
imprevista,es posible remediarlo hasta que desaparezca el
problema. Sin embargo, como no hay una teoría general
del funcionamiento de todo el [conjunto], éste no pasa a
ser un agregado caótico de subsistemas, cuya influencia en

${ }^{142}$ Comparar Jaramillo, Clientelismo y poder: relectura, 19.

${ }^{143}$ Ver Joseph Weizenbaujm, Computer Power and Human Reason: From Judgement to Calculation (San Francisco: Freeman, 1976), 119. “To hack is, according to the dictionary, 'to cut irregularly, without skill or definite purpose; to mangle by or as if by repeated strokes of a cutting instrument [...]' Programming systems [...] just as houses, cities, systems of dams, and national economic policies can be similarly hacked together. As a system so constructed begins to get large, however, it also becomes increasingly unstable. When one of its subfunctions fails in an unanticipated way, it may be patched until the manifest trouble disappears. But since there is no general theory of the whole system, the system itself can only be a more or less chaotic aggregate of subsystems whose influence on one another's behavior is discoverable only piecemeal and by experiment. The hacker spends part of his time at the console piling new subsystems onto the structure he has already built [...] and the rest of his time in attempts to account for the way in which substructures already in place misbehave [...] The act of modifying the then existing program invariably causes some of its substructures to collapse; they constitute, after all, an amorphous collection of processes whose interactions with one another are virtually fortuitous". 
la conducta mutua solo puede descubrirse fragmentariamente, por ensayo y error. El machetero gasta la mayoría de su tiempo [...] apilando nuevos subsistemas [correctivos], sobre una estructura ya establecida [...] [Para luego tratar] de explicar por qué esos subsistemas no operan adecuadamente [...] Las modificaciones del programa original indefectiblemente ocasionan el colapso de algunas subestructuras, debido a que al fin y al cabo éstas no son más que una aglomeración amorfa de procesos cuyas interacciones son virtualmente fortuitas. ${ }^{144}$

Arocha hace una crítica a las reformas de los años ochenta al señalar que las mismas institucionalizan elementos propios del clientelismo de tal manera que antes de darle muerte, se generan fenómenos aún más complejos.

No es complicado realizar un inventario de los "subprogramas correctivos" que quienes sustentan el poder han "macheteado" en 1979 desde sus "concolas" [consolas] de control político. Las reformas constitucional y de la justicia; el proyecto de estatuto indígena y la propuesta de reforma universitaria, entre otros, contienen elementos que institucionalizan e "involucran"las relaciones de clientela, fuera del ámbito político. Sin embargo, es dudoso su potencial estabilizador. Las declaraciones recientes de figuras políticas como el Dr. Echandía parecerían indicar que los “subprogramas macheteados" pueden llegar a erosionar el modelo que pretenden sustentar. ${ }^{145}$

${ }^{144}$ Ver Arocha Rodríguez, “Clientelismo”, 64.

${ }^{145}$ Ibid., 64. 
Por otro lado, David Roll afirma que el clientelismo moderno, tal como es conocido hoy día, si bien tuvo alguna presencia durante el Frente Nacional, sólo logró consolidarse completamente durante la etapa final del mismo; es decir, cuando más fue combatido. Según explica el autor, desde 1970 las élites políticas presentaron la necesidad, que con el paso de los gobiernos se fue haciendo progresiva, de utilizar mecanismos clientelistas que articularan el poder regional para lograr el triunfo de las elecciones. ${ }^{146}$

La metástasis del clientelismo a lo largo y a lo ancho del sistema político colombiano no tardó en elevar los costos de mantenimiento, el sostén y la reproducción de las clientelas. No en vano, los auxilios parlamentarios se convirtieron en fondos de financiación de las campañas políticas, que elevaron los costos de las mismas y limitaron la entrada de nuevos líderes a la arena política. ${ }^{147} \mathrm{Tal}$ aumento en los costos implicó acudir a fuentes de financiación privadas ilícitas o no. ${ }^{148} \mathrm{La}$ entrada de dineros ilegales al sistema político pronto produjo la injerencia de actores al margen de la ley en las decisiones tomadas por el mismo Estado.

Andrés Dávila no podría decirlo mejor: "[...] el clientelismo, durante un buen tiempo, le generó al régimen político colombiano la legitimidad suficiente para reproducirse y subsistir; pero, evidentemente, también generó algunas condiciones de ilegitimidad en la medida en que sectores de la población ya no se sentían parte del sistema político y empezaban a cuestionar la institucionalidad vigente". ${ }^{149}$

\footnotetext{
${ }^{146}$ Ver Roll, “El clientelismo”, 117-118.

${ }^{147}$ Comparar Dávila Ladrón de Guevara, "Clientelismo, intermediación”, 68.

${ }^{148}$ Comparar Jaramillo, Clientelismo y poder: relectura, 19.

${ }^{149}$ Ver Dávila Ladrón de Guevara, “Clientelismo, intermediación”, 68.
} 
En efecto, las clientelas fueron las formas de vinculación de los ciudadanos al Estado. Sin embargo, la reforma de 1968, junto con la crisis de representatividad que ya venían sufriendo los partidos, generó una situación sostenida de corrupción administrativa tanto por la apropiación de bienes públicos con fines privados como por la injerencia de dineros privados ilegales en el sector público. Con todo ello, el clientelismo devino en corrupción, y la forma tradicionalmente adoptada para hacer política fue satanizada, penalizada y, por supuesto, considerada como contrapuesta al paradigma reinante: el democrático.

Para Fernán González, el debate que inició el ex presidente Lleras Restrepo en contra del clientelismo se enmarcó dentro de un proyecto de modernización de la vida política mucho más amplio, que se sustentaba en la implantación del modelo de sustitución de importaciones y, por ende, en el respaldo a los intereses del sector industrial. Sin embargo, se complementaba con un modelo de democracia formal tipo burgués que de cualquier forma implicaba el aumento de la concentración del poder en manos de los poderosos sobre la imposibilidad de injerencia de los más débiles. El discurso anti clientelista sostenido por el sector "modernizante" en Colombia, hasta este momento, no contempló la implementación de una democracia en el sentido substancial.El ex presidente no calculó que el clientelismo es imposible de superar sin ciertas bases mínimas de igualdad social y económica. ${ }^{150}$

${ }^{150}$ Comparar González, “Clientelismo”, 71. 